\title{
MITO Y FÁBULA
}

The paper studies the relationship between fable and myth: their points of contact and their differences. At the beginning both genres were used as example, and often they were instructive or ethiological. They refer to stories which happened in old times. The characters are different, but no absolutely, because some gods appear in the fable, and some animals in the myth.

The fable differs from the myth because it deals with situations of all kind, it is innovative and flexible. Besides, it has a critical and satyric character. The paper ends giving a list of the fables on which there are divine characters: gods in conection with the creation of mankind, and erotic and comic gods.

Consideramos y consideraban los griegos en general el mito y la fábula como dos géneros diferentes, pese a que no existía diferencia ter-

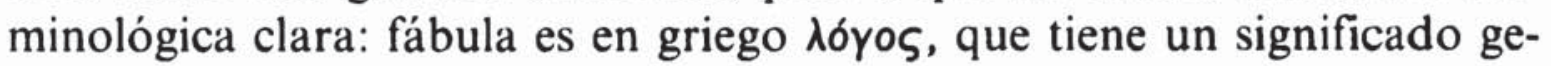
neral de relato, pero también $\mu \tilde{\theta} \theta o_{\varsigma}$, que otras veces se traduce por «mito». También fabula, en latín, significa las dos cosas. El mayor esfuerzo para la diferenciación terminológica es cuando la fábula es cono-

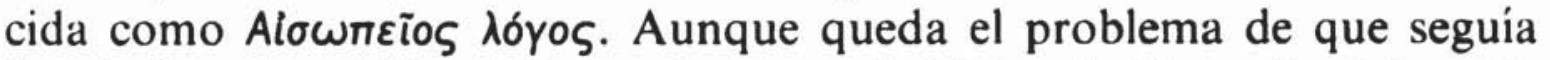
llamándose, también, $\mu \tilde{\theta} \theta$ os y de que se hablaba de $\lambda \delta$ yo sibaríticos, libicos, etc. ^óyos puede ser toda historia o relato, incluso mítico. Para todo esto remito a la exposición más detallada de mi Historia de la Fábula Greco-Latina' ${ }^{\text {. }}$

La parcial coincidencia terminológica procede, evidentemente, de una al menos parcial coincidencia de fondo. En ambos casos, se trata de relatos fictivos de hechos sucedidos en el origen de los tiempos; aunque para la fábula puede haber excepciones, tomarse como tales anécdotas contemporáneas. También hay mitos "recientes», en que un dios se aparece en cualquier momento a un personaje.

Pero, en lo esencial, se trata, como digo, expresa o implícitamente, de un tiempo antiguo, el del nacimiento de los dioses o sus aventuras, aquel en que hombres y dioses convivian, se amaban, se odiaban. Igual

${ }^{\prime}$ Madrid, Universidad Complutense, 1979, I, p. 28 ss. 
la fábula, que a veces se atribuye expresamente al tiempo en que los animales hablaban (Jenofonte, Mem. II 7, 13) o en que todos convivían pacificamente (Babrio 102).

Precisamente algunos mitos son etiológicos, explican hechos de la vida de hoy por lo sucedido en los origenes: los herreros solían ser cojos en Grecia porque su divino patrono, Hefesto, lo era; y lo era de resultas de su caída del Olimpo a Lemnos, arrojado por Zeus o por Hera, según las versiones. Calímaco dedicó un libro entero, los Aitia, a este tema. Pues, bien, también son etiológicas muchas fábulas, como veremos.

Y también hay coincidencia cuando nos referimos a la función del mito y de la fábula. Pongamos dos ejemplos, Hesíodo y Arquíloco.

En Trabajos y Dias toda la parte inicial de la obra, tras el proemio, está constituido por una serie de mitos y una fábula y su función es la misma: explicar cómo, por qué, son las cosas humanas como son. Hay competencia leal y hay envidia: esto es porque no fueron una, sino dos las Erides que engendró la Noche en el comienzo de los tiempos. Hay tantas desgracias en la tierra porque Zeus ocultó a los hombres los medios de vida para castigar el pecado de Prometeo y regaló a Epimeteo la primera mujer, Pandora, que por curiosidad abrió la tinaja en que estaban encerrados todos los males. Además, es que vivimos en la edad de hierro, que sigue a las edades precedentes, iniciadas por la de oro. Y es trabajosa la virtud y fácil el vicio porque así lo estableció Zeus.

Hablamos de mitos en todos estos casos, aunque es ambigua la clasificación de los relativos a Prometeo, que a veces aparecen en los fabulistas. Pero entre ellos se intercala una clara fábula, la del halcón y el ruiseñor. El halcón le dice al ruiseñor que lleva entre su garras y que se lamenta, que lo soltará o no según quiera, pues es más fuerte. Esto simboliza la dureza del mundo: así fue con un halcón y un ruiseñor que diríamos primordiales, así será. Aunque Hesíodo añade que Zeus concedió a los hombres la justicia, que puede elevarlos sobre ese nivel de la bestialidad.

Con mitos, fábulas y máximas Hesíodo alecciona a su injusto hermano Perses: le enseña cómo son de injustos el hombre y la vida, le indica que también hay la justicia que ayuda y la injusticia que trae malas consecuencias. Fábula y mito son elementos de crítica, de enseñanza, de parénesis. Abren las partes del poema en que Hesíodo enseña a su hermano los trabajos del campo y de la navegación para que pueda vivir sin injusticia.

Veamos ahora Arquíloco. La parte central de sus epodos contiene siempre lo que, con terminología medieval, llamariamos un enxiemplo o 
ejemplo. Es un mito en el Epodo XII: a un rival en amor el poeta le amenaza con el mito de Héracles y Neso, cuando este centauro, que hacía el transporte de personas a través del río Eveno, quiso abusar de Deyanira, la mujer de Héracles, y fue muerto por las flechas de éste. Pero otros ejemplos son propiamente fábulas animalísticas.

Por ejemplo, en el Epodo I la fábula del águila y la zorra, sobre la que hemos de volver, hace ver a Licambes, que ha roto su juramento de conceder al poeta la boda de su hija Neobula, que una impiedad siempre recibe castigo. Otros Epodos presentan las desventuras del mono, burlado por la zorra: es crítica y burla de los rivales del poeta. Neobula que, ya vieja, quiere seducir a Arquíloco, es rechazada con la fábula de la zorra que no quiso entrar en la cueva del león porque veía huellas de animales que entraban, pero no de otros que salieran.

Hay, ciertamente, dos diferencias, pero no son absolutas. La primera se refiere a los protagonistas. En los casos de diferencia más clara el mito nos presenta dioses, también héroes: hay el mito divino y el mito heroico, aunque en otros intervienen al tiempo dioses y héroes. A su vez, en los casos más claros la fábula nos presenta animales, a veces plantas, incluso seres inanimados como la lima o el muro o la alforja. Pero no hay límite entre estas fábulas y las que nosotros llamariamos anécdotas: por ejemplo, en Arquíloco la del adivino Batusíades, cuya casa era robada mientras él adivinaba para otros en la plaza. En otras fábulas, veremos, intervienen dioses o dioses y hombres o dioses y animales; y hay huella, también, del antiguo carácter divino del animal. O intervienen abstracciones divinizadas: Invierno y Verano, Fortuna, el Mar, la Muerte, etc.; son comparables a otras que intervienen en el mito, a veces son las mismas.

Otra diferencia se refiere al carácter crítico de la fábula y a sus rasgos cósmicos y de humor. A ellos ya aludía Aristófanes cuando en

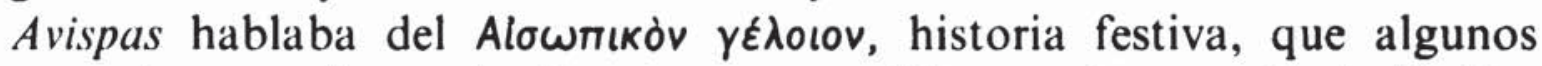
acusados contaban a los jueces para modificar su humor. Y aludía Fedro cuando en el prólogo a su libro I hablaba de iocari, jugar o divertirse.

Esta diferencia existe pero, como la anterior, es de grado. El mito puede usarse también con intención crítica, así el de Héracles y Neso por Arquíloco, según hemos visto, o el del naufragio de Ayax de Oileo, dirigido por Alceo $298 \mathrm{~V}$. contra Pitaco. Y hay el mito festivo como el de Hefesto arrojado del Olimpo en la Iliada (canto I) o, en la Odisea, el de los amores de Hefesto y Afrodita, cantados por Demódoco (canto VIII). Y tantos otros recordados por la Comedia y el Drama Satírico o que dieron lugar a conmemoraciones y fiestas populares en que lo có- 
mico y lo trágico se unían, como expuse más en detalle en mi Fiesta, Comedia y Tragedia ${ }^{2}$.

Lo que ha ocurrido en Grecia es que el mito se hace heroico y trágico en la epopeya y la tragedia, cómico en los géneros antes mencionados. Pero la fábula es también un género cómico y admite mitos cómicos relativos a ciertos dioses y héroes muy característicos: sobre todo, Hermes, Afrodita, Prometeo, Héracles y algunos más. Podemos, pues, calificarlos de fábulas. En fin, para el papel del mito en la vida de Grecia remito a un trabajo mío sobre este tema ( $« \mathrm{El}$ mito griego y la vida de Grecia») publicado en el Homenaje a Luis Diez del Corral ${ }^{3}$.

Pero vamos a estudiar más despacio la relación entre mito y fábula animal y vegetal. Hay que considerar que los dioses griegos apenas conservan elementos teriomórficos que son frecuentes en otras religiones emparentadas. Quedan en divinidades inferiores del tipo de los Sátiros o Panes o en algún resto arcaico como la Deméter arcadia de cabeza de yegua. Pero no en las superiores: todo lo más, se habla de Atenea de ojos de lechuza o Hera de ojos de vaca, se cuentan las metamorfosis míticas de Zeus o de Dioniso. Y quedan danzas rituales que imitan a los animales, antiguos dioses como dice Aristófanes de Las aves. Y animales asociados a dioses, como el águila a Zeus o la paloma a Afrodita.

Pues bien, la fábula, que es una versión popular, cómica, humorística del mito, conserva huellas de la proximidad del animal, en los origenes del mundo, a los dioses. Vamos a poner ejemplos de fábulas griegas que, en realidad, derivan de mitos.

Una es la ya citada del águila y la zorra: ésta pide a Zeus el castigo del águila, que había violado el pacto de amistad robando a las crías de la zorra; y Zeus hace que el águila sea castigada. Pues, bien es conocido que la fábula deriva del mito del poema Etana acadio en que el dios Samas castiga al águila que había traicionado su amistad con la serpiente. El águila es el animal sagrado de Samas o de Zeus, pero es castigada por ellos por su violación del juramento. ¿Llamaremos mito o fábula al relato de Arquiloco? En todo caso, en las versiones posteriores de la Augustana y de Fedro Zeus desaparece, sólo quedan los animales.

Paralelamente, he propuesto en otro lugar ${ }^{4}$ que en la fábula griega del águila y el escarabajo (H. 3, de Semónides 12) hay un influjo egipcio: el escarabajo, el sucio animal que castigó al águila y dejó a Zeus en

\footnotetext{
2 Madrid, Alianza Universidad, 1983, p. 398 ss.

${ }^{3}$ Madrid, Eudema, 1987, pp. 359-375.

4 "Sobre el origen de la fábula del águila y el escarabajo», en $C F C$ 21, 1988, pp. 261-266.
} 
ridículo, desciende del escarabajo egipcio, el animal sagrado que es símbolo de Ra y se eleva al cielo como el Sol.

$\mathrm{Y}$ véase, todavía, otro ejemplo bien claro: la fábula del asno y la serpiente en Ibico 61, en la que Prometeo da al animal la droga de la inmortalidad: la serpiente se rejuvenece al cambiar de piel. He hecho ver ${ }^{5}$ que se trata de un tema procedente del mito de Gilgamés, en el poema sumerio de este nombre.

El límite entre fábula y mito es sutil en casos como éstos. En otros, los animales de la fábula aparecen unidos a los momentos primordiales del mundo.

Uno es el tema de la danza de los animales y la elección, en ese contexto, de su rey. Este tema subyace, por ejemplo, a la fábula del mono rey en Arquíloco. Pero es que a veces es Zeus el que organiza el concurso: así en H. 103, «El cuervo y las aves».

Pero es más frecuente el tema de los animales que se quejan a Zeus de alguna insuficiencia que recibieron al ser creados: Zeus los castiga por rebelarse contra la naturaleza. Al camello que se quejaba de tener las orejas cortas, se las recortó aún más (H. 119); a las abejas, que le pedian poder matar con su aguijón, las hizo morir cuando picaran $(\mathbf{H}$. 172). También hay el tema de la embajada a Zeus, como la que enviaron las ranas para pedir un rey $($ H. 44) o los perros a Júpiter para pedirle que mejorara su suerte (Fedro IV 19): estas embajadas explican que todavia hoy la serpiente devore a las ranas o que los perros se huelan unos a otros el trasero.

La rebelión contra la naturaleza tiene siempre malas consecuencias. Así también cuando la comadreja, enamorada de un joven, pidió a Afrodita que la convirtiera en mujer. Estaba en el lecho con el enamorado cuando la diosa, para probarla, soltó un ratón: la joven salió corriendo tras él. Y la diosa la convirtió otra vez en comadreja. Estos temas continuaron vivos en la fábula incluso cuando desaparecieron los dioses. Así en el Speculum stultorum medieval cuyo protagonista el asno recorre las escuelas de medicina para que le alarguen la cola, con malas consecuencias.

No son estos los únicos temas en que hay presencia simultánea de un dios y un animal o un dios y un hombre: luego veremos ejemplos. Son fábulas etiológicas con algo de chistoso. Hay otras que no son etiológicas, en que el dios da un consejo u ofrece una solución.

Pero es que, incluso si no aparece el dios, el animal está a veces en un contexto en que es fácil encontrar en él algo de divino, ya dije antes.

"Cf. mi artículo "Ibico 61 y el influjo del Gilgamés en Grecia", Aula Orientalis 1, 1983, pp. 17-29. 
Si H. 39 explica por qué los hombres respetan los nidos que la golondrina pone en sus casas, es que se refiere en el fondo a esa golondrina que retorna todos los años y es celebrada como un dios en cantos populares bien conocidos. La serpiente, el águila, el león son prototipos originales de estos animales, provistos de rasgos que no cambian. El caballo que en H. 238 se deja montar por el hombre y queda para siempre esclavo de él es un caballo prototípico, original.

Pero, en todo caso, si prescindimos de los temas comunes con el mito y del valor diríamos que mítico del animal en ciertas fábulas, éstas, en general, se han distanciado ya del mito lo suficiente para que sean ese género aparte, popular, didáctico, satírico, de que hemos hablado. Igual las que hacen intervenir plantas cuyas características quedan fijadas para siempre, así "El laurel y el olivo» de Calímaco, Iamb. 3. Una fábula como la de Fedro III 17, Arbores in deorum tutela, donde cada dios elige un árbol para ponerlo bajo su protección, deja ver bien claro el carácter sacral, divino de los mismos. La planta maravillosa de Paráfrasis 85 , lo confirma.

Pero prescindamos de momento de los problemas de orígenes y los problemas de límites. Es cierto, en definitiva, que la fábula animal y vegetal difiere del mito por sus personajes y presenta con la mayor frecuencia un carácter de crítica o humor. Y hay otras cosas más.

El mito se refiere a una tradición difundida con personajes divinos o heroicos con nombre propio, por así decirlo. Cierto que el mito presenta a veces alternativas, variantes, y que, en una cierta medida, permite una modificación por parte de los poetas. Pero fundamentalmente es estable. La fábula, en cambio, hace posible la libre invención. Hay, simplemente, fábulas que han tenido éxito y han producido luego múltiples variantes o derivados: así la del cuervo y la zorra o la de la golondrina y las aves o la del labrador y la serpiente. Pero hay, además, muchísimas fábulas libremente inventadas.

Se ha calculado que la colección de Demetrio contendría unas 100 fábulas; pues bien, las fábulas antiguas que he recogido en el vol. III de mi Historia ${ }^{6}$ (y me refiero a los prototipos, no a las variantes) son unas 500. Muchísimas de ellas fueron creadas por los cínicos: hacen intervenir temas o animales nuevos, propios de ellos. Otras son de creación posterior.

$\mathrm{Y}$ es que el mito se refiere, fundamentalmente, a los grandes momentos de la vida humana: nacimientos, enfrentamientos decisivos, amor, muerte. También, ya se ha dicho, puede referirse a la etiología de

\footnotetext{
${ }^{6}$ Madrid 1987.
} 
sucesos y costumbres. La fábula, aparte de a la etiología, se centra en los enfrentamientos de animales y plantas. A veces son enfrentamientos en que se juega la vida de una de las partes, la del cordero frente al lobo, por ejemplo. Otras veces son más lúdicos o simbólicos: el cuervo lo que pierde, al enfrentarse con la zorra, es un pedazo de queso.

La infinita riqueza de la vida humana, incluso a niveles humildes, es reflejada por la fábula. Los muchísimos animales que en ella intervienen simbolizan los distintos tipos de hombres; y la acción entre ellos, los muchísimos tipos de acciones de la vida real. La fábula es mucho más flexible, adaptable que el mito. Y tiene literalmente una estructura diferente: es un breve relato con una organización simple y constante, a base de presentar una situación, un enfrentamiento estereotipado y una conclusión. Otras veces hay fábulas de situación, con un solo personaje que la comenta: así la del pescador y el pulpo en Simónides 9. Remito a una descripción más detallada que dice en mi Historia, vol. I, y en mi trabajo «La fábula griega como género literario» ${ }^{7}$. El mito es más complejo.

Estoy hablando de la fábula animal, complementada con la vegetal y con aquella que hace intervenir objetos animados, que también tienen un valor simbólico. Pero ya he dicho que hay otro sector de la fábula que nosotros llamariamos mejor, quizá, anécdota. Comparte algunas de las características críticas, lúdicas, simbólicas de la fábula, su estructura composicional es la misma. Pero introduce personajes humanos: hombre frente a hombre o frente a dios o frente a animal.

Desde el comienzo estos relatos fueron colocados al lado de la fábula y del mito: ya he aludido a la anécdota o fábula del adivino en Arquíloco (Epodo V). Cuando se hicieron las colecciones de fábulas, relatos de este tipo fueron incluidos: el del adivino, por ejemplo, aparece como fábula $\dot{H}$. 170. A algunos de ellos, incluso de los que hacen intervenir dioses, los llamariamos nosotros, mejor, cuentos. Así a los cuentos eróticos del tipo del de la viuda de Éfeso (H. 299).

Asi, por poner un ejemplo, citemos la fábula de Hermes y el leñador (H. 183). El leñador pierde su hacha en el río y Hermes le devuelve una de oro. Pero él dice que no es la suya, ni tampoco la de plata que Hermes le da luego; finalmente, acepta la devolución de la realmente suya. Otro leñador, codicioso, tira su hacha al río y Hermes le ofrece una de oro: él quiere aceptarla, diciendo que es la suya. Pero el dios no le da ni la de oro ni la suya. Aquí hay que ver que la aparición del dios, la

\footnotetext{
${ }^{7}$ En Estudios sobre los géneros literarios, Cáceres 1982, pp. 33-46.
} 
estructura compleja y el castigo del malo (raro en la fábula) se alejan un tanto del centro del género y se aproximan al cuento.

Pero, en fin, y sin entrar en estos distingos, es claro que la fábula animal puede introducir al hombre. Así, entre las fábulas de tradición antigua, la del labrador y la serpiente desagradecida, que le mordió después que él la había calentado en su seno (H. 62); entre las cínicas, la de la mujer y la gallina de los huevos de oro (H. 89). Pero puede tratarse del hombre y el dios o una hipóstasis equivalente, así cuando la Muerte se le aparece al viejo (H. 60). O de un animal y un dios, ya lo hemos visto. $\mathrm{O}$ puede tratarse de dos dioses: se enfrentan Bóreas y el Sol, Zeus y Apolo, Héracles y Pluto: pero no son mitos antiguos, más bien anécdotas en que los dioses tienen un papel simbólico, como el de los animales. Naturalmente hay fábulas a base de un solo hombre (como la del adivino) o de dos enfrentados (como la de la mujer y la criada, H. 55).

En todo caso, lo que une estos relatos a las fábulas animalísticas y vegetales es su estructura simple, su intención y su gran flexibilidad. En fecha reciente, helenística y romana, se han difundido y creado en gran número. Es que son más capaces todavía que la fábula animal de exponer la infinita multiplicidad de lo humano. Y de exponer las situaciones humanas dentro de una sociedad muy concreta, la contemporánea. Idénticas posibilidades se dieron, por lo demás, en otras sociedades, tales la india y la medieval europea, que a su vez utilizaron las mismas fábulas antiguas y crearon otras nuevas.

Éste es el mundo de la fábula, mucho más libre y adaptable que el del mito, más vivo y fructífero. Da un panorama entre realista e irónico, también crítico, de la vida humana. Predica una cierta moralidad pero no se deja engañar sobre la verdad de las cosas. Se refiere a la humanidad en general en los temas del poder y tantos otros, pero también a las situaciones concretas de una sociedad. Siendo la fábula, en principio, un pendant realista y popular del mito, un sector desgajado de él, conserva afinidades, pero tiene, también, características propias muy acusadas. Y tiene mayor vitalidad, capacidad de renovación, de adaptación, de novedad.

Y, con esto, vamos a ofrecer un catálogo en que se apuntan brevemente las fábulas en que intervienen dioses o hipóstasis divinizadas. En qué medida algunas pueden calificarse de mitos, es cosa debatible. En todo caso, su tipología está calcada sobre la de mitos de creación (y etiológicos en general) o de enfrentamiento entre dioses o de acciones en que un dios se aparece a un hombre: son los tres grupos que distinguimos. Pero, como las demás fábulas, éstas están creadas libremen- 
te, no son tradicionales. Y están íntimamente relacionadas con otras en que ya no aparecen los dioses, según hemos expuesto más arriba.

Exponemos, pues, los tres grupos uno tras otro. Para las fábulas que no están en las Anónimas (fábulas $\mathrm{H}$.), doy el número de mi recopilación en Historia, vol. III (fábulas no $\mathrm{H}$.).

\section{Fábulas de la creación y etiológicas en general}

Veamos primero aquellas en que interviene Zeus.

H. 44 "Las ranas pidiendo rey». Las ranas envían un mensajero a Zeus y la serpiente que éste les envía (antes les envió un leño, que ellas rechazaron) las devora.

H. 104 «Hermes y la Tierra». Hay el enfrentamiento entre los dos dioses, como en las fábulas del grupo siguiente, pero lo central es la creación del hombre por Zeus y su destino mortal.

H. 108 "Zeus y la tortuga». Zeus condena a la tortuga a llevar la casa a cuestas, por haber llegado tarde a la boda del dios y haberse disculpado con su amor a la casa.

H. 109 "Zeus y la zorra». Zeus concedió a la zorra el reino de los animales por su inteligencia, pero soltó un escarabajo y la zorra fue a cogerlo: demostró que seguía siendo zorra y en zorra quedó.

H. 110 «Zeus y los hombres». Al crear a los hombres, ordenó a Hermes que los llenara de inteligencia. Los pequeños se llenaron, los grandes no. De ahí su insensatez.

H. 111 «Zeus y la Vergüenza». Etiología de la desvergüenza de los homosexuales, en relación con el mito de la creación.

H. 119 «Zeus y el camello». Etiología del pequeño tamaño de las orejas de este animal, véase más arriba.

H. 172 "Lás abejas y Zeus». Etiología de por qué las abejas mueren cuando clavan el aguijón, véase más arriba.

No H. 27 (Calímaco, Iamb. II) "La charlatanería de los hombres». Deriva de que Zeus, en la creación, quitó la palabra a los animales, dándosela a los hombres.

No H. 104 (Platón, Symp. 189 c) «El Amor». Explicación del amor hetero- y homosexual por el mito de los hombres esféricos que Zeus partió en dos.

No H. 105 (Himerio, Ecl. 10, 6) «El Amor entre los hombres». Zeus se lo envió a los hombres para que no se extinguiera la raza humana.

No H. 114 (Fedro, App. 3, de Platón, Prt. 320 c ss.) «Zeus, los animales y el hombre». Zeus infundió a los hombres el Pudor y la Justicia, para compensarles de sus inferioridades. 
No H. 115 (Babrio 58, de Hesíodo, Op. 90 ss.) «Zeus y la tinaja de bienes". El que los bienes estén tan lejos de los hombres deriva de que abrieron la tinaja llena de ellos que Zeus les regaló: sólo quedó la Esperanza.

No H. 161 (Fedro, IV 19) «Los perros que enviaron mensajeros a Zeus». Véase más arriba.

No H. 228 (Vida de Esopo, 33, de Eurípides, IT 1259 ss.) «Sueños verdaderos y falsos». Unos y otros fueron creados por Zeus cuando entregó a Apolo el oráculo de Delfos.

No H. 245 (Plutarco, Cons. Ap. 12 a) «El privilegio del Duelo». Zeus concedió a Duelo, como privilegio, lágrimas y dolores. Cuanto más se llora, más se sufre.

Emparentado con este tema está el ya aludido arriba del concurso organizado por el dios para nombrar rey de las aves. En H. 103 «El grajo y las aves", el primer animal se adorna con plumas ajenas y cuando Zeus va a elegirlo aquéllas se las arrebatan y es expulsado. En no $\mathrm{H}$. 247 (Babrio 56) "La madre del mono y Zeus», la madre del mono presenta a su hijo al concurso de belleza, cree que es el más bello.

Los temas etiológicos están en otras ocasiones referidos a otros dioses:

A Hermes: tema de H. 105 «Hermes», explicación de por qué los zapateros mienten más que nadie (este servidor de Zeus les echó más droga de la mentira que a nadie); de no $\mathrm{H}$. 101 «El carro de Hermes y los árabes», explicación de por qué los árabes mienten tanto: vaciaron la carreta de Hermes (anécdota, no mito de creación).

A Prometeo:

H. 292 «El león, Prometeo y el elefante». Prometeo consoló al león que se quejaba de su miedo al gallo: que vea cómo el elefante teme al mosquito.

No H. 254 (Suetonio, Tib. 57; Temistio, Or. 32) «Prometeo cuando modeló la raza humana». Prometeo amasó la arcilla con que creó al hombre no con agua, sino con lágrimas. De ahí sus infortunios.

No H. 267 (Fedro IV 15) «Prometeo». Prometeo creó la lengua de las mujeres de sus partes sexuales.

No H. 268 (Fedro IV 16) "Prometeo borracho". Un error de Prometeo borracho creó a los maricas y lesbianas.

No H. 269 (Pedro, App. 5-6). Prometeo modeló la Verdad; y el Engaño, al que confió un momento su taller, la Mentira. Fabricada a toda prisa, no tiene pies.

A Hefesto: no H. 244 (Hesíodo, Op. 90 ss., Th. 570 ss.) «Pandora». 
La creó, por encargo de Zeus, como regalo envenado a los hombres; y, en efecto, dejó escapar los males de su tinaja.

A Afrodita: tema de H. 50 "La comadreja y Afrodita», véase más arriba; de no H. 33 (Plutarco 303 c) "Afrodita y el mercader» (explicación de un epíteto de Afrodita en Samos; viene de la recomendación de la diosa a un mercader).

A Dioniso: tema de no H. 84 (Paníasis $13 \mathrm{~K}$ ), explicación de los efectos del vino: una copa da placer, dos alegría, tres hybris.

A Juno: tema de no H. 259 (Fedro III 18) «El pavo a Juno sobre su voz». Ante las quejas del pavo, que se quejaba de tener belleza, pero no canto, la diosa le dijo que se conformara, cada especie tiene ventajas y desventajas.

A Minerva: tema de no H. 48 (Fedro III 17) "Los árboles bajo la protección de los dioses». Minerva eligió el olivo por su fruto. Júpiter le dio la razón.

Como se ve, las fábulas de esta relación están generalmente en el contexto de la creación, a veces se han independizado más y son simples anécdotas. El contexto de la creación explica la aparición de Zeus y de servidores suyos como Hermes, Prometeo y Hefesto. Otros dioses sólo figuran en conexión con temas que son propios de ellos: el amor (Afrodita), el vino (Dioniso), el pavo (Juno), el olivo (Minerva).

Curiosamente, Gregorio de Nacianzo (no H. 102 = Poem. Moral., M. 37,3 , p. 898 «El origen del rubor») inventó una fábula cristiana en que el protagonista es Dios, que envió a los hombres el Rubor para distinguir a los buenos de los malos.

$\mathrm{Y}$, como hemos dicho, temas comparables aparecen sin intervención de los dioses. Así, ya en Aristófanes (no H. 142, Aristófanes, $A u .471$ ss.), la fábula de la alondra que en los comienzos del mundo enterró al padre en la cabeza, de donde su moño. $Y$ en época medieval el tema del asno que quiere en vano tener una cola más larga, véase más arriba.

\section{Fábulas agonales}

Prescindimos de las fábulas agonales humanas o animales, también de algunas vegetales $(\mathrm{H} .71$ "La encina y la caña»; no H. 79; Calímaco, Iamb. IV «El laurel y el olivo"; no H. 272, Par. Bodl. 324 "La rosa y el amaranto"). Fuera de ellas encontramos unas pocas en que en enfrentamiento se produce entre dioses y más en que tiene lugar entre hipóstasis divinizadas. Siempre se refieren a un enfrentamiento cuyo resultado tiene importancia aleccionadora para la vida humana. 
H. 46 «Bóreas y el Sol». La enseñanza es que «más vale maña que fuerza».

H. 91 «Hermes y Tiresias». Si dios quiere, Tiresias recobrará los bueyes que Hermes le ha robado. Sátira religiosa, sobre el tema del robo de las vacas de Apolo por Hermes.

H. 113 "Héracles y Pluto». Cuando Héracles, en su apoteosis, llega al cielo, no quiere saludar a Pluto, pues siempre lo ve en compañía de los malos. Crítica cínica de la riqueza, continuadora del tema de la virtud y el vicio en Hesiodo y Pródico.

H. 102 «Zeus, Prometeo, Atenea y Momo». Serie de enfrentamientos de los dioses con Momo, que todo lo critica. Zeus, indignado, lo expulsa del Olimpo.

H. 106 "Zeus y Apolo». En el concurso del arco, por lejos que tire Apolo, lo sobrepasa Zeus, incluso de una zancada.

H. 297 «El Invierno y el Verano». Triunfa el Verano.

No H. 28 (Hermesianacte en Plutarco, Fluu. 2-3) «Apolo, las Musas y las Dríades». Disputa entre el Citerón y el Helicón, sede el uno de las Erinis, el otro de las Musas.

No H. 97 (Plutarco, Them. 18) «La Fiesta y el Día Siguiente». La Fiesta cansa, pero sin ella no hay Día Siguiente.

No H. 117 (Platón, Phaed. 60b) «El Placer y el Dolor». Fábula que, según Sócrates, podría haber inventado Esopo para hacer ver que el placer y el dolor siempre van unidos.

No H. 131 (Fedro, App. 11). Juno representa la castidad, Venus compara a las mujeres con las gallinas aludiendo a su avidez sexual.

No H. 214 (Aristid., Or. 27, 236) "Momo y Afrodita». Momo, dispuesto a criticar algo en Afrodita, al fin criticó sus zapatillas. Siempre hay algo que criticar. rosa,

H. 248 "Zeus y la Serpiente». De la Serpiente Zeus no acepta ni la

No H. 250 (Babrio 70) «La Guerra y la Violencia». Guerra (masc.) se casó con Violencia: van siempre juntas.

No H. 251 (Platón, Smp. 203 a ss.) "El recurso y la Pobreza». De la unión de ambos nace Eros, feo, pero buscador de belleza.

No H. 252 (Sintipas 4) "Los Ríos y el Mar». Disputa: los ríos se quejan de que el mar los vuelve salados, él les dice que no entren.

No H. 277 (Plutarco, Mor. 157 a, de Cleobulo o Cleobulina) «La Luna y su Madre». Imposible hacerle un vestido a la Luna, siempre crece o mengua. 
Los enfrentamientos entre dioses, animales, plantas, abstracciones, son antiguos no sólo en Grecia, también en Mesopotamia ${ }^{8}$. En Grecia, desde Platón se construyen nuevas fábulas sobre este tema para simbolizar temas filosóficos. Incluso se contamina, enfrentando a un dios y un animal o un hombre (sobre esto véase a continuación).

\section{El dios frente al hombre}

Con frecuencia, el dios saca las consecuencias o hace el comentario de una acción humana.

H. 35 «El hombre y el sátiro». El hombre se sopla las manos para aliviar el frío y el calor; el sátiro no quiere saber nada de una conducta tan contradictoria.

H. 60 «El viejo y la muerte». El viejo que llamaba a la muerte cuando acarreaba un haz de leña, al presentarse ella le pide que le ayude a llevar el fardo. Tema del amor a la vida.

H. 61 «El labrador y la Fortuna». El labrador agradece a la Tierra el hallazgo de un tesoro y la Fortuna se queja de que a ella sólo le atribuyan las desgracias.

H. 112 "El héroe». Un hombre sacrificaba a un héroe cuya imagen guardaba, pero éste se le apareció diciéndole que dejara de sacrificar pues iba a arruinarse y le echarian a él la culpa.

Sátira religiosa.

H. 184 «El caminante y Hermes». El caminante se duerme junto a un pozo y la Fortuna le dice que si se hubiera caido le habrian echado a ella la culpa.

No H. 1 (Par. Bodl. 1) "Los Bienes y los Males». Los Bienes, refugiados en el cielo, volvieron a los hombres separadamente, por consejo de Zeus: de ahí su rareza.

No H. 13 (Babrio 126) "La Verdad». Vive en el desierto y dice que ahora la Mentira es la que se halla entre todos los hombres.

No H. 59 (Babrio 20) «El boyero y Hermes». Hay que trabajar, no basta con orar, dice Héracles al boyero cuyo carro se había caido a un barranco.

No H. 82 (Babrio 117) «El hombre mordido por la serpiente y Hermes». Al hombre que se queja de la injusticia de los dioses, Hermes le dice que por qué pisa él despreocupadamente a una hormiga.

\footnotetext{
${ }^{\star}$ Cf. Historia, vol. I, p. 317 ss.
} 
No H. 85 (Babrio 10) «La esclava y Afrodita». El hombre enamorado de una esclava sacrificaba agradecido a Afrodita, pero ésta le dijo que ese amor era más bien un castigo.

No H. 99 (Babrio 30) "Hermes y el escultor». Ante un escultor que vendía un Hermes que uno quería como estatuta de culto, otro como estela funeraria, el dios se le apareció ironizando.

No H. 119 (Par. Bodl. 130). Cuantos más golpes da Héracles con la clava a una manzana, más crece. Atena explica que es la ambición.

Claro que la acción puede invertirse y ser el hombre el que da al dios una buena respuesta: en H. 90 "Hermes y el escultor» es éste el que le dice al dios, que se presenta en su taller preguntando por el precio de una imagen suya, que si se lleva las de Zeus y Hera, le regala ésta.

Otras veces no se trata de una máxima, sino de una acción divina que resuelve la situación.

H. 183 «El leñador y Hermes». Premio del hombre honrado y castigo del malo, véase más arriba.

H. 214 «El que recibió un depósito y el Juramento». Aunque se cree que éste llega tarde a reclamar el castigo del perjuro, a veces llega pronto.

No H. 68 (Par. Bodl. 85) «El labrador y la planta». Tema del árbol sagrado, al que el labrador reverencia. En una ocasión, no H. 146 (Sintipas 48) «El Cíclope», el personaje mítico actúa de otro modo: el Cíclope se suicidó al ver que el hombre que había ido a suicidarse se había apoderado de su tesoro.

Todo éste es, parece, material reciente. Sobre el tema común del dios que simboliza algo o tiene un determinado poder, que da una máxima o consejo, se han creado pequeños mitos o fábulas sin tradición anterior como las que hemos visto.

Se ve, pues, que independientemente de los elementos que la fábula tenga en comunidad con el mito, del que por otra parte se ha diferenciado grandemente, utiliza elementos míticos, tradicionales, para proliferar y renovarse.

Francisco Rodríguez Adrados 